\title{
Comparison of time to failure of pembrolizumab plus chemotherapy versus pembrolizumab monotherapy: a consecutive analysis of patients having NSCLC with high PD-L1 expression
}

\author{
Hiroshi Takumida $^{1}$ (D) Hidehito Horinouchi ${ }^{1}$ (D) Ken Masuda ${ }^{1}$ Yuki Shinno $^{1} \cdot$ Yusuke Okuma $^{1}$ (D) Tatsuya Yoshida ${ }^{1}$. \\ Yasushi Goto $^{1}$. Noboru Yamamoto ${ }^{1}$ (D) Yuichiro Ohe ${ }^{1}$ (D)
}

Received: 6 June 2021 / Accepted: 4 August 2021 / Published online: 14 August 2021

(c) The Author(s) 2021

\begin{abstract}
Introduction There are two treatment strategies for non-small cell lung cancer (NSCLC) exhibiting a high expression level of programmed death-ligand 1 (tumor proportion score $\geq 50 \%$ ): pembrolizumab plus chemotherapy and monotherapy. We retrospectively compared their efficacy and safety.

Materials and methods We reviewed the efficacy and safety of first-line pembrolizumab-containing regimens administered between 2017 and 2020 to consecutive patients. The patients were divided into a pembrolizumab plus chemotherapy group (Combo group) or monotherapy group (Mono group). To compare the efficacy, we monitored the time to failure of strategy (TFS) defined as the time from the start of treatment to the occurrence of one of the following events: the addition of any drug not included in the primary strategy, progression of cancer after complete therapy, progression and no subsequent therapy, or death, whichever occurred first. We used the propensity score matching (PSM) to reduce the bias.

Results A total of 126 patients were identified (89 in the Mono group and 37 in the Combo group). PSM matched 36 individuals from each of the two groups. The overall response rate and median progression-free survival of the Combo group were better than those of the Mono group. However, the median TFS was almost the same (11.3 months vs. 14.9 months; hazard ratio 1.40 [95\% confidence interval 0.62-3.15]). The frequency of all serious adverse effects was higher in the Combo group than in the Mono group.

Discussion Due to similar efficacy in TFS, both pembrolizumab plus chemotherapy and monotherapy are valid options for NSCLC.
\end{abstract}

Keywords Non-small cell lung cancer · Immune checkpoint inhibitors · Drug therapy · Pembrolizumab · PD-L1 · Time to failure of strategy

\section{Introduction}

Several trials have demonstrated the efficacy of pembrolizumab, an immune checkpoint inhibitor, in patients with advanced non-small cell lung cancer (NSCLC) exhibiting a high expression level of programmed death-ligand 1 (PDL1) (tumor proportion score [TPS] $\geq 50 \%$ ) [1-4]. For example, the KEYNOTE-024 trial showed that pembrolizumab monotherapy was effective for patients with TPS $>50 \%$,

Hidehito Horinouchi

hhorinou@ncc.go.jp

1 Department of Thoracic Oncology, National Cancer Center Hospital, 5-1-1 Tsukiji, Chuo-ku, Tokyo 104-0045, Japan regardless of the histology [1]. The subset analysis of the KEYNOTE-042 trial, in which pembrolizumab was administered to patients with TPS $>1 \%$, also showed consistent results [2]. In other trials that evaluated the efficacy of the addition of pembrolizumab to platinum doublet chemotherapy, the combination therapy was superior to chemotherapy alone in a subset analysis of the KEYNOTE-189 trial and the KEYNOTE-407 trial, respectively. The KEYNOTE-189 trial showed the efficacy of cisplatin or carboplatin + pemetrexed $(\mathrm{PEM})+$ pembrolizumab in non-squamous cell carcinoma [3]. The KEYNOTE-407 trial showed the efficacy of platinum + (nanoparticle albumin-bound [nab-]) paclitaxel $(\mathrm{PTX})+$ pembrolizumab in patients with squamous cell carcinoma [4]. 
However, there is no clear consensus on whether pembrolizumab monotherapy followed by chemotherapy or combined pembrolizumab plus chemotherapy is superior for the treatment of advanced NSCLC with PD-L1 TPS $\geq 50 \%$. Moreover, there has been only an indirect comparison between the two strategies. For example, in the 4-year follow-up data of the KEYNOTE-189 trial, the 3-year survival rate of the TPS high population was $43.7 \%$ [5], which is comparable with the 3 -year survival rate $(43.7 \%)$ in the analysis of the 5-year follow-up data of the KEYNOTE-024 trial [6]. There are other two reports used real-world data; however, the trend was similar [7, 8]. The significance of combining chemotherapy is not clear when comparing these results.

To address these questions, we retrospectively compared the efficacy and safety of pembrolizumab monotherapy and pembrolizumab plus platinum doublet therapy.

\section{Materials and methods}

\section{Study design and patients}

We consecutively reviewed patients with NSCLC (aged $\geq 18$ years) with a PD-L1 TPS $\geq 50 \%$ who received first-line treatment with pembrolizumab between 2017 and 2020 at the National Cancer Center Hospital, Japan. The patients were divided into two groups: a pembrolizumab monotherapy group (Mono group) and a combined pembrolizumab plus chemotherapy group (Combo group). We then evaluated the TFS, which was defined as the time from the start of treatment to the occurrence of one of the following events: the addition of any drug not in the primary strategy, progression of cancer after complete therapy, progression and no subsequent therapy, or death, whichever occurred first. Moreover, we evaluated the objective response rate (ORR), progression-free survival (PFS), overall survival (OS), and safety.

To reduce the bias in the choice of regimen, we excluded patients who had been previously treated with chemotherapy, such as perioperative chemotherapy, chemoradiotherapy, or those who received pembrolizumab in the clinical trial. We also excluded patients with confirmed positive driver oncogenes. Furthermore, we used the propensity score matching (PSM) method to reduce the selection bias due to the patient background.

\section{Data collection}

The value of PD-L1 TPS was defined as described in a previous clinical trial [1]. All values were determined using the PD-L1 IHC 22C3 pharmDx assay (Agilent Dako). Efficacy was determined according to the New Response Evaluation
Criteria in Solid Tumors: Revised RECIST guideline (version 1.1) [9]. Adverse events (AEs), including abnormalities in the results of laboratory investigations, were graded according to the National Cancer Institute Common Terminology Criteria for Adverse Events, version 5.0 [10] until the beginning of the second line of treatment. Serious adverse events (SAEs) were defined as AEs resulting in death or risk of death, hospitalization for treatment, or prolonged hospitalization. The cut-off date was April 30, 2021.

\section{Statistical analysis}

PSM was applied at a ratio of 1:1 with a caliper width equal to 0.2 of the standard deviation of the logit of the propensity score to compare the pembrolizumab monotherapy group and the pembrolizumab plus chemotherapy group. Factors, such as age, sex, smoking history, PD-L1 TPS, history of lung disease, performance status, histology, and staging, were matched.

The follow-up period, TFS, PFS, and OS were estimated using the Kaplan-Meier method. Data of the patients who were alive or lost to follow-up were censored for OS when they were last known to be alive. Data of patients who were alive and did not have disease progression or those who were lost to follow-up were censored for the analysis of PFS or TFS at the time of the last imaging assessment.

The hazard ratios (HRs) and 95\% confidence intervals (CIs) were calculated using the Cox proportional hazards model. HR and 95\% CI after PSM were calculated using the stratified Cox proportional hazards model. All statistical analyses were performed using the EZR (Easy R) statistical software version 1.54 [11]. Statistical significance was set at $p<0.05$.

\section{Results}

\section{Patient selection}

Of the 964 patients with advanced NSCLC who underwent first-line treatment, 303 patients received a pembrolizumabcontaining regimen. The number of patients with a PD-L1 high TPS was 168 . Forty-two patients were excluded from the study. Therefore, 126 patients were included in the analysis. The pembrolizumab monotherapy group comprised 89 patients, and the combined pembrolizumab plus chemotherapy group comprised 37 . The PSM matching identified 36 individuals from each of the two groups (Fig. 1). The median follow-up period of the pembrolizumab monotherapy group was 30.3 months (range $0.1-40.8$ months), and that of the 
Fig. 1 Patient selection. Analysis of the data of patients with advanced-stage NSCLC from 2017 to 2020 was performed. Eighty-nine patients were assigned to the Combo group, and 37 patients were assigned to the Mono group. PSM matched 36 people from each of the two groups. NSCLC, non-small cell lung cancer; PD-L1, programmed death-ligand 1; TPS, tumor proportion score; PSM, propensity score matching

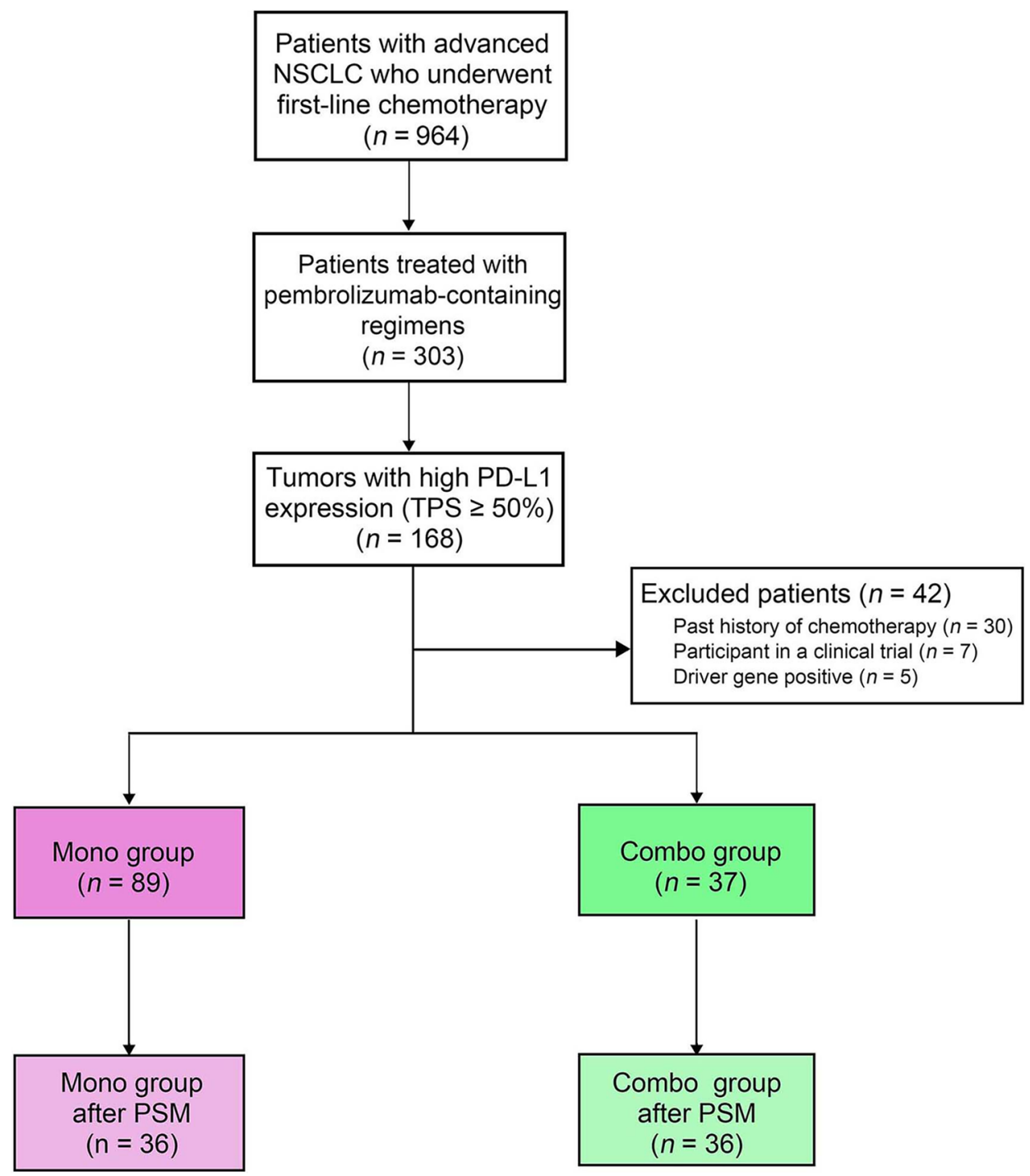

combined pembrolizumab plus chemotherapy group was 19.2 months (range 2.3-27.9 months).

\section{Patients' characteristics (Table1)}

The regimen of platinum + PEM + pembrolizumab was administered to 30 patients $(81.1 \%)$ in the combined pembrolizumab plus chemotherapy group, and the regimen of platinum + (nab-) PTX + pembrolizumab was administered to seven patients $(18.9 \%)$. Patients in the pembrolizumab monotherapy group were older and had worse performance status at baseline (PS), and a higher proportion of patients had a history of lung disease. The percentage of patients with relapse of the disease was higher in the pembrolizumab monotherapy group than in the pembrolizumab plus chemotherapy group. We used PSM to adjust for factors that differed between groups or were clinically important;
PSM allowed the pembrolizumab monotherapy group and the pembrolizumab plus chemotherapy group to be almost identical in age, PS, and staging. The number of patients with history of lung diseases decreased in the pembrolizumab monotherapy group after PSM.

\section{First-line treatment}

The ORR was $43.8 \%$ in the pembrolizumab monotherapy group and $67.6 \%$ in the pembrolizumab plus chemotherapy group. The disease control rate was $64.0 \%$ in the pembrolizumab monotherapy group and $94.6 \%$ in the pembrolizumab plus chemotherapy group. These results did not change after PSM (supplementary Table 1). The median PFS (mPFS) was also significantly longer in the pembrolizumab plus chemotherapy group than in the pembrolizumab monotherapy 
Table 1 Patients' characteristics

\begin{tabular}{|c|c|c|c|c|c|}
\hline Characteristics & $\begin{array}{l}\text { All } \\
\text { groups } \\
(n=126)\end{array}$ & $\begin{array}{l}\text { Mono } \\
\text { group } \\
(n=89)\end{array}$ & $\begin{array}{l}\text { Mono group } \\
\text { after PSM } \\
(n=36)\end{array}$ & $\begin{array}{l}\text { Combo } \\
\text { group } \\
(n=37)\end{array}$ & $\begin{array}{l}\text { Combo } \\
\text { group after } \\
\text { PSM } \\
(n=36)\end{array}$ \\
\hline \multicolumn{6}{|l|}{ Regimen, n (\%) } \\
\hline Pembrolizumab & $89(70.6)$ & $89(100.0)$ & $36(100.0)$ & $0(0.0)$ & $0(0.0)$ \\
\hline Platinum + PEM + Pembro & $30(23.8)$ & $0(0.0)$ & $0(0.0)$ & $30(81.1)$ & $30(83.3)$ \\
\hline Platinum + (nab-) PTX + Pembro & $7(5.6)$ & $0(0.0)$ & $0(0.0)$ & $7(18.9)$ & $6(17.7)$ \\
\hline Age in years, median (range) & $68.5(38-94)$ & $69(38-94)$ & $66(45-80)$ & $64(46-78)$ & $64(46-78)$ \\
\hline \multicolumn{6}{|l|}{ Smoking status, n (\%) } \\
\hline Current or former & 107(84.9) & $76(85.3)$ & $32(88.9)$ & $31(83.8)$ & $30(83.3)$ \\
\hline Never & $19(15.1)$ & 13(14.6) & $4(11.1)$ & $6(16.2)$ & $6(17.7)$ \\
\hline Male sex, n (\%) & $92(73.0)$ & $65(73.0)$ & $27(75.0)$ & $27(73.0)$ & $27(75.0)$ \\
\hline \multicolumn{6}{|l|}{ Performance status, $n(\%)$} \\
\hline 0 or 1 & $97(77.0)$ & $65(73.0)$ & $33(91.7)$ & $32(86.5)$ & $31(86.1)$ \\
\hline$\geq 2$ & $29(23.0)$ & $24(27.0)$ & $3(8.3)$ & $5(13.5)$ & $5(13.9)$ \\
\hline History of lung disease, $n(\%)$ & $57(45.2)$ & $46(51.7)$ & 15(41.6) & 11(29.7) & 11(30.6) \\
\hline \multicolumn{6}{|l|}{ Stage, $n(\%)$} \\
\hline IV & $89(70.6)$ & $55(61.8)$ & 33(91.7) & 34(91.9) & 33(91.7) \\
\hline $\begin{array}{l}\text { Recurrence } \\
\text { Other }\end{array}$ & $\begin{array}{l}31(24.6) \\
6(4.8)\end{array}$ & $\begin{array}{l}28(31.5) \\
6(6.7)\end{array}$ & $\begin{array}{l}3(8.3) \\
0(6.7)\end{array}$ & $\begin{array}{l}3(8.1) \\
0(0.0)\end{array}$ & $\begin{array}{l}3(8.3) \\
0(0.0)\end{array}$ \\
\hline \multicolumn{6}{|l|}{ Histology, $n(\%)$} \\
\hline Ad & $77(61.1)$ & $51(57.3)$ & $23(63.9)$ & $26(70.3)$ & $26(72.2)$ \\
\hline $\mathrm{Sq}$ & $25(19.8)$ & $19(21.3)$ & $3(8.3)$ & $6(16.2)$ & $5(13.9)$ \\
\hline Other & $24(19.0)$ & $19(21.3)$ & $10(27.8)$ & $5(13.5)$ & $5(13.9)$ \\
\hline \multicolumn{6}{|l|}{ Tumor PD-L1 status, $n(\%)$} \\
\hline $\mathrm{TPS} \geq 75 \%$ & $86(68.3)$ & $60(67.4)$ & $29(80.1)$ & $26(63.4)$ & $26(72.2)$ \\
\hline $75 \%>\mathrm{TPS} \geq 50 \%$ & $40(31.8)$ & $29(32.6)$ & $7(19.4)$ & $11(26.8)$ & $10(27.8)$ \\
\hline
\end{tabular}

$A d$, adenocarcinoma; $P D-L 1$, programmed cell death-ligand 1; PEM, pemetrexed; Pembro, pembrolizumab, PSM, propensity score matching; PTX, paclitaxel; nab-PTX, nanoparticle albumin-bound paclitaxel; $S q$, squamous cell carcinoma; TPS, tumor proportion score

group (11.3 months vs. 6.8 months; HR 0.58 [95\% CI 0.34-0.97]) (Fig. 2a), and these results did not change after PSM (Fig. 2b).

\section{Time to failure of strategy (TFS)}

To compare the efficacy of the two treatments, we used TFS, which was defined as the time from the start of treatment to the occurrence of one of the following events: the addition of any drug not in the primary strategy, progression of cancer after complete therapy, progression and no subsequent therapy, or death, whichever occurred first.

In contrast to the PFS, the median TFS (mTFS) was not significantly different between the two groups (11.3 months vs. 13.5 months; HR 1.09 [95\% CI 0.63-1.87]) (Fig. 2c), and these trends did not change after PSM (11.3 months vs. 14.9 months; HR 1.40 [95\% CI 0.62-3.15]) (Fig. 2d).

\section{Second-line treatment in the pembrolizumab monotherapy group}

In the pembrolizumab monotherapy group, the proportion of patients who received second-line treatment after disease progression was $49.2 \%$ ( 31 out of 63 patients). A platinumcontaining regimen was administered to $74 \%$ of patients who received second-line treatment (23 patients). In regimens, including PEM, $72 \%$ of patients transitioned to maintenance therapy. The ORR of second-line treatment was 41.9\% (13 patients of 31). After PSM, the proportion of patients who received second-line treatment after disease progression was 67.9\% (19 patients of 28), and a platinum-containing regimen was used in $63.1 \%$ of patients who received second-line treatment (12 patients). The ORR of the second regimen was $42.1 \%$ (8 patients of 19). After PSM, there was an increase in the proportion of patients who received second-line treatment after pembrolizumab treatment. However, the efficacy of the treatment did not change. 

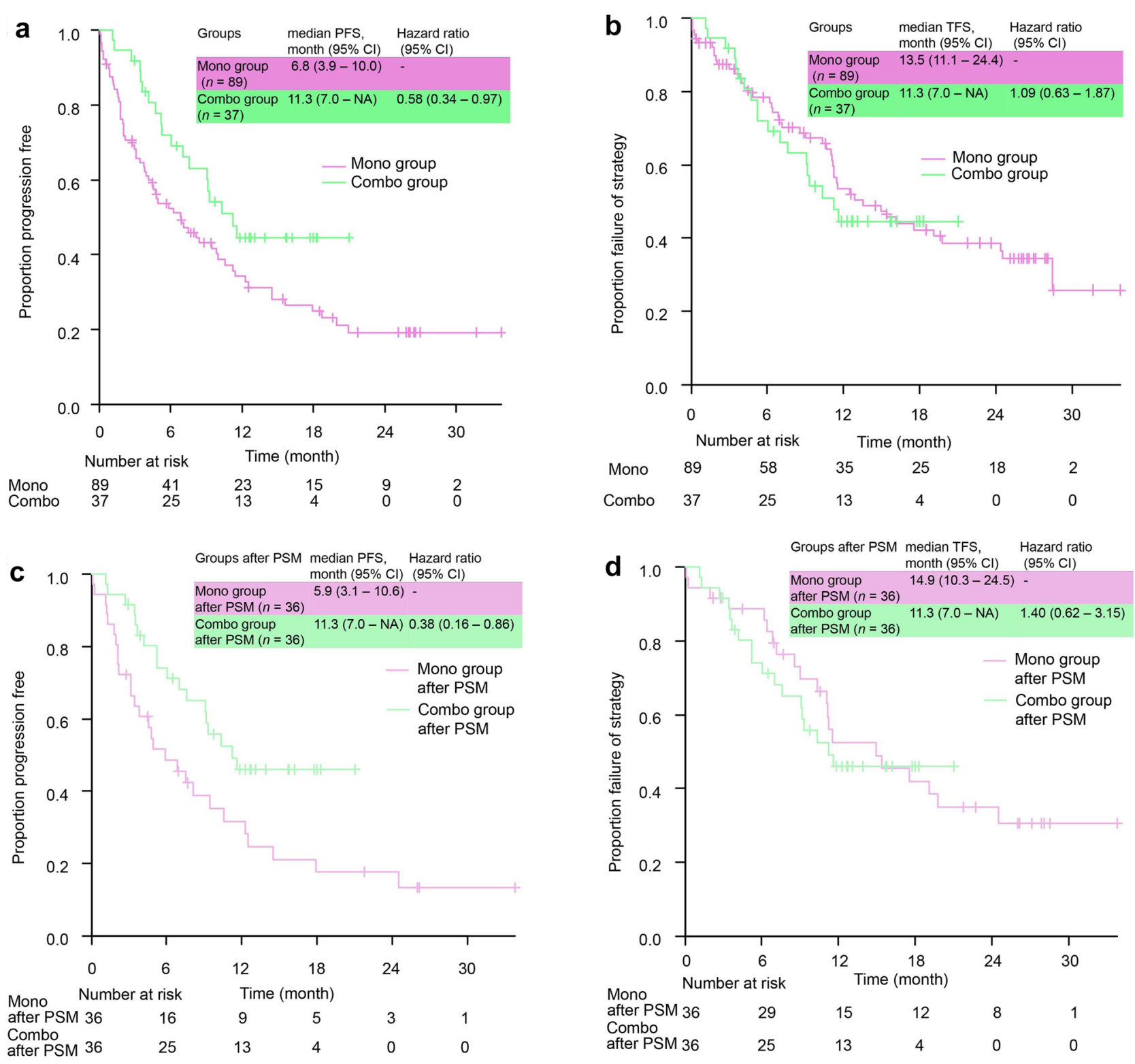

Fig. 2 Survival curve a Progression-free survival, b Time to failure of strategy, c Progression-free survival after PSM, d Time to failure of strategy after PSM. PFS and TFS were estimated using the Kaplan-Maier method. PFS was significantly longer in the pembrolizumab plus chemotherapy group than in the pembrolizumab monotherapy group, and this trend did not change after PSM (HR

\section{Overall survival}

The median OS was not different between the groups (Fig. 3a), and it was consistent after PSM (Fig. 3b). However, OS was immature because only $27.0 \%$ (10 patients) in the pembrolizumab plus chemotherapy group died in the observation period. In contrast, $47.1 \%$ (42 patients) in the pembrolizumab monotherapy group died. For the efficacy, i.e., ORR, PFS, TFS, and OS, subgroup analysis was

0.38 [95\% CI 0.16-0.86], stratified Cox proportional hazards model). TFS was almost the same and this trend did not change after PSM, too (HR 1.40 [95\% CI 0.62-3.15], stratified Cox proportional hazards model). PSM, propensity score matching; PFS, progression-free survival; TFS, time to failure of strategy; CI, confidence interval; NA, not applicable

performed by histological type, whether it was squamous cell carcinoma, but the trend did not change significantly (supplementary Table 2 and supplementary Fig. 1). However, subset analysis in squamous cell carcinoma should be evaluated cautiously due to substantially small number of patients with squamous histology. 


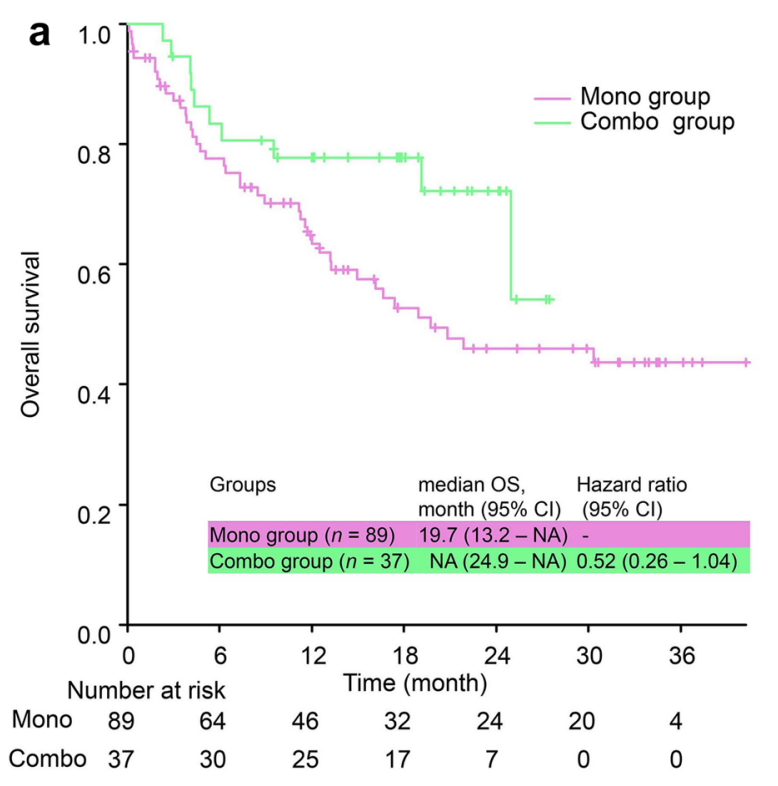

Fig. 3 Overall survival, a Overall survival of the two groups. b Overall survival after PSM. OS was estimated using the Kaplan-Maier method. However, the data are immature because of the large number of censored patients. The median OS in the Pembro + Chemo group

\section{Adverse events (Table 2)}

In the pembrolizumab plus chemotherapy group, AEs related to cytotoxic anticancer agents, including hematopoietic disorders, hepatic dysfunction, renal dysfunction, fatigue, and gastrointestinal symptoms, were more frequent than that in the pembrolizumab monotherapy group, indicating that the combination regimens were more toxic than monotherapy. There were also a large number of SAEs related to chemotherapy. The frequency of immune-related AEs (irAEs) was slightly lower in the pembrolizumab plus chemotherapy group; furthermore, pneumonia and infusion reactions were less frequent.

AEs leading to treatment discontinuation were also more common in the pembrolizumab plus chemotherapy group than that in the pembrolizumab monotherapy group. There were two treatment-related deaths in the pembrolizumab monotherapy group (2.2\%) and one in the pembrolizumab plus chemotherapy group (2.8\%). These trends did not change after the PSM.

\section{Discussion}

The combination of pembrolizumab plus chemotherapy or pembrolizumab monotherapy followed by chemotherapy demonstrated a similar TFS and OS for patients with advanced NSCLC exhibiting a high PD-L1 TPS. ORR and PFS were higher in the pembrolizumab plus chemotherapy

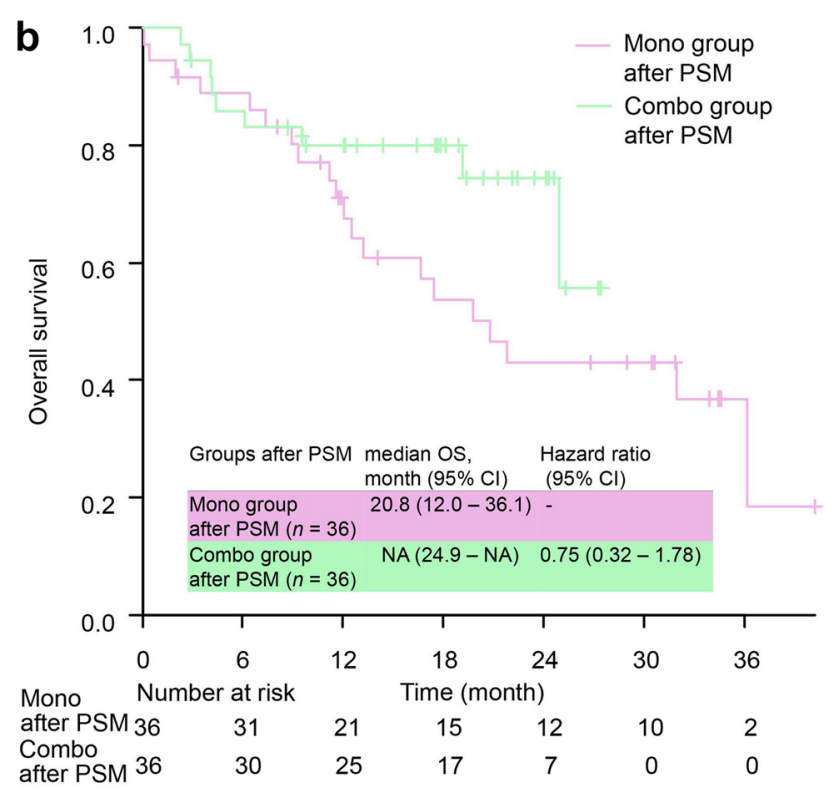

tended to be slightly better, but the difference narrowed after PSM (HR 0.75 [95\% CI 0.32 - 1.78], stratified Cox proportional hazards model). PSM, propensity score matching; OS, overall survival; CI, confidence interval; NA, not applicable

group. These trends did not change after the PSM. In terms of safety, the pembrolizumab plus chemotherapy group had more AEs associated with chemotherapy and consequently had a higher frequency of treatment discontinuation and modifications.

A similar trend has been observed in previous clinical trials. The PFS with monotherapy is approximately 7 months [6, 12], and the PFS with combination therapy was 11.1 months in patients with non-squamous cell carcinoma[13] and 8.0 months in patients with squamous cell carcinoma[4]. However, these differences in PFS did not reflect long-term survival. As mentioned earlier, the 3-year survival rate is approximately $40 \%$ in clinical trials of both monotherapy and combined chemotherapy [5, 14]. Moreover, in terms of safety, in this study, the treatment discontinuation rate was comparable to that in previous studies $[2,6$, 13, 15]: The treatment discontinuation rate of combination therapy was approximately $30 \%$, and that of monotherapy was approximately $10 \%$.

To the best of our knowledge, there is no report focusing on TFS that has examined the strategy of combination immunotherapy and chemotherapy versus immunotherapy alone. The comparison of PFS2 which was defined as progression after a subsequent therapy line or death, whichever occurs first in the past clinical trials, is not consistent with the clinical practice strategy because the number of drugs used is different since chemotherapy followed by platinum combination therapy (e.g., DTX) was administered to the experimental group. TFS has been proposed as a surrogate 
Table 2 Adverse events

\begin{tabular}{|c|c|c|c|c|c|c|c|c|}
\hline \multirow[t]{2}{*}{ Event } & \multicolumn{2}{|c|}{$\begin{array}{l}\text { Mono group } \\
(n=89)\end{array}$} & \multicolumn{2}{|c|}{$\begin{array}{l}\text { Mono group } \\
\text { after PSM } \\
(n=36)\end{array}$} & \multicolumn{2}{|c|}{$\begin{array}{l}\text { Combo group } \\
(n=37)\end{array}$} & \multicolumn{2}{|c|}{$\begin{array}{l}\text { Combo group } \\
\text { after PSM } \\
(n=36)\end{array}$} \\
\hline & Any grade & Grade 3 or 4 & Any grade & Grade 3 or 4 & Any grade & Grade 3 or 4 & Any grade & Grade 3 or 4 \\
\hline \multicolumn{9}{|l|}{ Number of patients (\%) } \\
\hline Any event (not irAE) & 88(98.9) & $48(53.9)$ & $36(100.0)$ & $22(61.1)$ & $37(100.0)$ & $27(73.0)$ & $36(100.0)$ & $26(72.2)$ \\
\hline WBC count decreased & $0(0.0)$ & $0(0.0)$ & $0(0.0)$ & $0(0.0)$ & $26(70.3)$ & $9(24.3)$ & $25(69.4)$ & $9(25.0)$ \\
\hline Neutrophil count decreased & $0(0.0)$ & $0(0.0)$ & $0(0.0)$ & $0(0.0)$ & $24(64.9)$ & $14(37.8)$ & $24(66.7)$ & 14(38.9) \\
\hline Lymphocyte count decreased & $35(39.3)$ & $10(11.2)$ & $13(36.1)$ & $4(11.1)$ & $22(59.5)$ & $11(29.7)$ & $21(58.3)$ & $11(30.6)$ \\
\hline Febrile neutropenia & $0(0.0)$ & $0(0.0)$ & $0(0.0)$ & $0(0.0)$ & $5(13.5)$ & $5(13.5)$ & $5(13.9)$ & $5(13.9)$ \\
\hline Anemia & $32(36.0)$ & $8(9.0)$ & $13(36.1)$ & $2(5.6)$ & $32(86.5)$ & $11(29.7)$ & $31(86.1)$ & $11(30.6)$ \\
\hline Platelet count decreased & $12(13.5)$ & $2(2.2)$ & $4(11.1)$ & $0(0.0)$ & $26(70.3)$ & $6(16.2)$ & $26(72.2)$ & $6(16.7)$ \\
\hline Constipation & $18(20.2)$ & $0(0.0)$ & $7(19.4)$ & $0(0.0)$ & $31(83.8)$ & $0(0.0)$ & $30(83.3)$ & $0(0.0)$ \\
\hline Anorexia & $24(27.0)$ & $3(3.4)$ & $10(27.8)$ & $0(0.0$ & $28(75.7)$ & $2(5.4)$ & $28(77.8)$ & $2(5.6)$ \\
\hline Nausea & $22(24.7)$ & $1(1.1)$ & $12(33.3)$ & $0(0.0)$ & $23(62.1)$ & $1(2.7)$ & $23(63.9)$ & $1(2.8)$ \\
\hline Malaise & $36(40.4)$ & $4(4.5)$ & $15(41.7)$ & $2(5.6)$ & $21(56.8)$ & $1(2.7)$ & $21(58.3)$ & $1(2.8)$ \\
\hline AST increased & $42(47.2)$ & $4(4.5)$ & $19(52.8)$ & $3(8.3)$ & $28(75.7)$ & $2(5.4)$ & $28(77.8)$ & $2(5.6)$ \\
\hline ALT increased & $41(46.0)$ & $4(4.5)$ & $16(44.4)$ & $3(8.3)$ & $23(62.1)$ & $1(2.7)$ & $22(61.1)$ & $1(2.8)$ \\
\hline Hypoalbuminemia & $44(49.4)$ & $10(11.2)$ & $18(50.0)$ & $2(5.6)$ & $22(59.5)$ & $2(5.4)$ & $21(58.3)$ & $2(5.6)$ \\
\hline Creatinine increased & $23(25.8)$ & $0(0.0)$ & $9(25.0)$ & $0(0.0)$ & $15(40.5)$ & $0(0.0)$ & 14(38.9) & $0(0.0)$ \\
\hline Any irAE & $64(71.9)$ & $13(14.6)$ & $28(77.8)$ & $8(22.2)$ & $26(70.3)$ & $4(10.8)$ & $25(69.4)$ & $4(11.1)$ \\
\hline Eczema & $42(47.2)$ & $2(2.2)$ & $20(55.6)$ & $1(2.8)$ & $18(48.6)$ & $0(0.0)$ & $17(47.2)$ & $0(0.0)$ \\
\hline Pneumonitis & $22(24.7)$ & $5(5.6)$ & $9(25.0)$ & $2(5.6)$ & $4(10.8)$ & $1(2.7)$ & $4(11.1)$ & $1(2.8)$ \\
\hline Hypothyroid & $16(18.0)$ & $0(0.0)$ & $4(11.1)$ & $0(0.0)$ & $4(10.8)$ & $0(0.0)$ & $4(11.1)$ & $0(0.0)$ \\
\hline Colitis & $13(14.6)$ & $2(2.2)$ & $4(11.1)$ & $0(0.0)$ & $4(13.3)$ & $1(2.7)$ & $4(11.1)$ & $1(2.8)$ \\
\hline Hyperthyroidism & $9(10.1)$ & $0(0.0)$ & $3(8.3)$ & $0(0.0)$ & $3(8.1)$ & $0(0.0)$ & $3(8.3)$ & $0(0.0)$ \\
\hline Infusion related reaction & $5(5.6)$ & $0(0.0)$ & $4(11.1)$ & $0(0.0)$ & $0(0.0)$ & $0(0.0)$ & $0(0.0)$ & $0(0.0)$ \\
\hline Adrenal insufficiency & $4(4.5)$ & $1(1.1)$ & $2(5.6)$ & $1(2.8)$ & $0(0.0)$ & $0(0.0)$ & $0(0.0)$ & $0(0.0)$ \\
\hline Arthralgia & $2(2.2)$ & $1(1.1)$ & $1(2.8)$ & $1(2.8)$ & $2(5.4)$ & $0(0.0)$ & $2(5.6)$ & $0(0.0)$ \\
\hline Hepatitis & $2(2.2)$ & $0(0.0)$ & $2(5.6)$ & $0(0.0)$ & $2(5.4)$ & $1(2.7)$ & $2(5.6)$ & $1(2.8)$ \\
\hline All SAE & $38(42.7)$ & & $16(44.4)$ & & $19(51.4)$ & & $19(52.8)$ & \\
\hline SAE (not irAE) & $13(14.6)$ & & $6(16.7)$ & & $12(32.4)$ & & $12(33.3)$ & \\
\hline SAE (irAE) & $29(32.6)$ & & $12(33.3)$ & & $12(32.4)$ & & $11(30.6)$ & \\
\hline Treatment discontinuation & $29(32.6)$ & & $11(30.6)$ & & $19(51.5)$ & & $18(50.0)$ & \\
\hline Treatment-related death & $2(2.2)$ & & $1(2.8)$ & & $1(2.7)$ & & $1(2.8)$ & \\
\hline
\end{tabular}

$A E$, adverse effect; $i r A E$, immune-related adverse effect; $A S T$, aspartate transaminase; $A L T$, alanine transaminase; $S A E$, serious adverse effect; $W B C$, white blood cell

endpoint for OS in colon cancer where multiple drugs are used sequentially [16]. Shinno et al. suggested that TFS might be a better surrogate endpoint for OS than PFS in NSCLC, where multiple sequential drug regimens are available such as in epidermal growth factor receptor-positive lung cancer [17]. When efficacious therapies such as immunotherapy can be used as both first-line and second-line therapies, the TFS might serve as a more appropriate surrogate endpoint for OS than PFS. Although OS in this study is immature and requires further validation, we suggest that both pembrolizumab plus chemotherapy and monotherapy are valid options with similar efficacy in TFS for patients with advanced NSCLC exhibiting a high PD-L1 TPS.

This study had several limitations. First, this was a retrospective, single-center study, which might have led to bias in the regimen selection. However, the patients were not arbitrarily excluded but were consecutively enrolled and adjusted to use PSM to reduce the bias. Second, because the timing and frequency of image evaluation differed from patient to patient, subjective bias could come into play. Nevertheless, all patients were regularly followed up every one to two months at the outpatient clinic and were examined by 
X-ray, CT, and MRI every 3 to 6 months. Finally, some AEs were possibly overlooked because AEs were collected solely from the medical records. However, the frequency of irAEs of grade 3 or higher did not differ significantly between the previous clinical trials and the current study; the frequency was $13.2 \%$ in the KEYNOTE-024 study [14] and $14.6 \%$ in this study.

Immunotherapy is an expensive treatment, and its economic impacts need to be considered. In the USA, both monotherapy and combination therapy were suggested to be more cost-effective than chemotherapy $[18,19]$; however, Barbier et al. suggested that the cost-effectiveness of combination therapy is marginal compared to monotherapy in Switzerland [20]. Moreover, combination therapy is more toxic than monotherapy. We need to select a more appropriate population for combination therapy. For example, because combination therapy exhibited a higher response rate than monotherapy, pembrolizumab plus chemotherapy could be more beneficial in patients who require a higher response, such as those with higher tumor volume and/or fast-growing tumors. Several prospective randomized studies are ongoing, and the INSIGNA trial (NCT03793179) and the NHO-Pembro-NSCLC trial (jRCTs031200078) will evaluate the efficacy of a combination of pembrolizumab and platinum + PEM for non-squamous cell carcinoma. These studies might lead to further clarity regarding these two strategies.

In conclusion, because of similar efficacy in TFS, both pembrolizumab plus chemotherapy and monotherapy would be valid options for patients with advanced NSCLC exhibiting a high PD-L1 TPS. However, combination therapy is more toxic as a first-line treatment. When efficacious therapies such as immunotherapy can be used as both first-line and second-line therapies, the TFS might serve as an appropriate surrogate endpoint for OS.

Supplementary Information The online version contains supplementary material available at https://doi.org/10.1007/s00262-021-03029-9.

Acknowledgements A summary of this paper was presented at the 2021 ASCO Annual Meeting, held on June 4-8, 2021.

Authors' contributions CRediT author statement. HT was involved in conceptualization, methodology, formal analysis, investigation, data curation, writing - original draft, and visualization. HH was involved in conceptualization, validation, resources, data curation, and writing-review and editing. KM, YS, YO, TY, YG, and NY were involved in resources and writing - review and editing. YO was involved in resources, writing-review and editing, supervision, and project administration.

Funding This research did not receive any specific grant from funding agencies in the public, commercial, or not-for-profit sectors.
Availability of data and material The datasets used and analyzed during the current study are available from the corresponding author on reasonable request.

\section{Declarations}

Conflict of interest Dr. Takumida has nothing to disclose. Dr. Horinouchi reports grants and personal fees from MSD, personal fees from Lilly, grants and personal fees from AstraZeneca, grants and personal fees from BMS, grants and personal fees from Ono, personal fees from Merck Biopharma, grants from Daiichi-Sankyo, grants from AbbVie, grants and personal fees from Janssen, grants from Genomic Health, grants and personal fees from Chugai, personal fees from Kyowa-Kirin, and personal fees from Nihonkayaku, outside the submitted work. Dr. Masuda reports personal fees from Chugai and personal fees from AstraZeneca, outside the submitted work. Dr. Shinno reports personal fees from Pfizer, personal fees from AstraZeneca, personal fees from Chugai Pharmaceutical, grants from Japan Clinical Research Operations K.K., grants from Janssen Pharmaceutical K.K., and grants from Ono Pharmaceutical, outside the submitted work. Dr. Okuma reports grants from AbbVie G.K., personal fees from Astra Zeneca, grants and personal fees from Chugai, and personal fees from Eli Lilly, outside the submitted work. Dr. Yoshida reported receiving grants and personal fees from AstraZeneca, grants and personal fees from BristolMyers Squibb, AbbVie, Merck Sharp \& Dohme, Ono Pharmaceutical, and Chugai, personal fees from Novartis, Taiho Pharmaceutical, Eli Lilly, Boehringer Ingelheim, Roche Diagnostics, and Archer, and grants from Takeda Pharmaceutical outside the submitted work. Dr. Goto reports grants and personal fees from Eli Lilly, personal fees from Chugai, grants and personal fees from Taiho Pharmaceutical, personal fees from Boehringer Ingelheim, grants and personal fees from Pfizer, grants and personal fees from Novartis, personal fees from AstraZeneca, grants and personal fees from MSD, grants and personal fees from Guardant Health, grants and personal fees from Ono Pharmaceutical, grants from Kyorin, grants and personal fees from Daiichi Sankyo, personal fees from Illumina, and grants and personal fees from Bristol-Myers Squibb, outside the submitted work. Dr. Yamamoto reports grants from Chugai, grants from Taiho, grants from Eisai, grants from Lilly, grants from Quintiles, grants from Astellas, grants from BMS, grants from Novartis, grants from Daiichi-Sankyo, grants from Pfizer, grants from Boehringer Ingelheim, grants from Kyowa-Hakko Kirin, grants from Bayer, grants from Ono Pharmaceutical Co., Ltd., grants from Takeda, personal fees from Ono Pharmaceutical Co., Ltd., personal fees from Chugai, personal fees from AstraZeneca, personal fees from Pfizer, personal fees from Lilly, personal fees from BMS, personal fees from Eisai, personal fees from Otsuka, personal fees from Takeda, personal fees from Boehringer Ingelheim, personal fees from Cimic, grants from Janssen Pharma, grants from MSD, grants from Merck, personal fees from Sysmex, grants from GSK, grants from Sumitomo Dainippon, grants from Chiome Bioscience Inc., grants from Otsuka, and grants from Carna Biosciences, outside the submitted work. Dr. Ohe reports grants and personal fees from AstraZeneca, grants and personal fees from Chugai, grants and personal fees from Ono, grants and personal fees from BMS, grants and personal fees from Kyorin, personal fees from Celltrion, personal fees from Amgen, personal fees from Nippon Kayaku, grants and personal fees from Eli Lilly, personal fees from Boehringer Ingelheim, personal fees from Bayer, grants and personal fees from Pfizer, personal fees from MSD, grants and personal fees from Taiho, personal fees from Kyowa Hakko Kirin, grants from Dainippon-Sumitomo, grants from Novartis, grants from Ignyta, grants from Takeda, grants from Kissei, grants from Daiichi-Sankyo, grants from Janssen, and grants from Loxo, outside the submitted work. 
Ethical approval This study was conducted in accordance with the Declaration of Helsinki. The study protocol was approved by the Certified Review Board of the National Cancer Center Hospital (2015-355). Patients were provided with an information disclosure document explaining the study and were excluded from the analysis if they opted out.

Open Access This article is licensed under a Creative Commons Attribution 4.0 International License, which permits use, sharing, adaptation, distribution and reproduction in any medium or format, as long as you give appropriate credit to the original author(s) and the source, provide a link to the Creative Commons licence, and indicate if changes were made. The images or other third party material in this article are included in the article's Creative Commons licence, unless indicated otherwise in a credit line to the material. If material is not included in the article's Creative Commons licence and your intended use is not permitted by statutory regulation or exceeds the permitted use, you will need to obtain permission directly from the copyright holder. To view a copy of this licence, visit http://creativecommons.org/licenses/by/4.0/.

\section{References}

1. Reck M, Rodríguez-Abreu D, Robinson AG, Hui R, Csőszi T, Fülöp A, Gottfried M, Peled N, Tafreshi A, Cuffe S, O’Brien M, Rao S, Hotta K, Leiby MA, Lubiniecki GM, Shentu Y, Rangwala R, Brahmer JR (2016) Pembrolizumab versus Chemotherapy for PD-L1-Positive Non-Small-Cell Lung Cancer. N Engl J Med. https://doi.org/10.1056/NEJMoa1606774

2. Mok TSK, Wu Y, Kudaba I, Kowalski DM, Cho BC, Turna HZ, Castro G Jr, Srimuninnimit V, Laktionov KK, Bondarenko I, Kubota K, Lubiniecki GM, Zhang J, Kush D, Lopes G, Adamchuk G, Ahn M, Alexandru A, Altundag O, Alyasova A, Andrusenko $\mathrm{O}$, Aoe K, Araujo A, Aren O, Arrieta Rodriguez O, Ativitavas T, Avendano O, Barata F, Barrios CH, Beato C, Bergstrom P, Betticher D, Bolotina L, Bondarenko I, Botha M, Buddu S, Caglevic C, Cardona A, Castro G Jr, Castro H, Cay Senler F, Cerny CAS, Cesas A, Chan G, Chang J, Chen G, Chen X, Cheng S, Cheng Y, Cherciu N, Chiu C, Cho BC, Cicenas S, Ciurescu D, Cohen G, Costa MA, Danchaivijitr P, De Angelis F, de Azevedo SJ, Dediu M, Deliverski T, De Marchi P, Martins R, de The Bustamante Valles, Flor, Ding Z, Doganov B, Dreosti L, Duarte R, Edusma-Dy R, Emelyanov S, Erman M, Fan Y, Fein L, Feng J, Fenton D, Fernandes G, Ferreira C, Franke FA, Freitas H, Fujisaka Y, Galindo H, Galvez C, Ganea D, Gil N, Girotto G, Goker E, Goksel T, Gomez Aubin G, Gomez Wolff L, Griph H, Gumus M, Hall J, Hart G, Havel L, He J, He Y, Hernandez Hernandez C, Hespanhol V, Hirashima T, Ho CMJ, Horiike A, Hosomi Y, Hotta K, Hou M, How SH, Hsia T, Hu Y, Ichiki M, Imamura F, Ivashchuk O, Iwamoto Y, Jaal J, Jassem J, Jordaan C, Juergens RA, Kaen D, Kalinka-Warzocha E, Karaseva N, Karaszewska B, Kazarnowicz A, Kasahara K, Katakami N, Kato T, Kawaguchi T, Kim JH, Kishi K, Kolek V, Koleva M, Kolman P, Koubkova L, Kowalyszyn R, Kowalski D, Koynov K, Ksienski D, Kubota K, Kudaba I, Kurata T, Kuusk G, Kuzina L, Laczo I, Ladrera GEI, Laktionov K, Landers G, Lazarev S, Lerzo G, Lesniewski Kmak K, Li W, Liam CK, Lifirenko I, Lipatov O, Liu X, Liu Z, Lo SH, Lopes V, Lopez K, Lu S, Martinengo G, Mas L, Matrosova M, Micheva R, Milanova Z, Miron L, Mok T, Molina M, Murakami S, Nakahara Y, Nguyen TQ, Nishimura T, Ochsenbein A, Ohira T, Ohman R, Ong CK, Ostoros G, Ouyang X, Ovchinnikova E, Ozyilkan O, Petruzelka L, Pham XD, Picon P, Piko B, Poltoratsky A, Ponomarova O, Popelkova P, Purkalne G, Qin S, Ramlau R,
Rappaport B, Rey F, Richardet E, Roubec J, Ruff P, Rusyn A, Saka H, Salas J, Sandoval M, Santos L, Sawa T, Seetalarom K, Seker M, Seki N, Seolwane F, Shepherd L, Shevnya S, Shimada AK, Shparyk Y, Sinielnikov I, Sirbu D, Smaletz O, Soares JPH, Sookprasert A, Speranza G, Srimuninnimit V, Sriuranpong V, Stara Z, Su W, Sugawara S, Szpak W, Takahashi K, Takigawa N, Tanaka H, Tan Chun Bing J, Tang Q, Taranov P, Tejada H, Tho LM, Torii Y, Trukhyn D, Turdean M, Turna H, Ursol G, Vanasek J, Varela M, Vallejo M, Vera L, Victorino A, Vlasek T, Vynnychenko I, Wang B, Wang J, Wang K, Wu Y, Yamada K, Yang C, Yokoyama T, Yokoyama T, Yoshioka H, Yumuk F, Zambrano A, Zarba JJ, Zarubenkov O, Zemaitis M, Zhang L, Zhang L, Zhang X, Zhao J, Zhou C, Zhou J, Zhou Q, Zippelius A, (2019) Pembrolizumab versus chemotherapy for previously untreated, PD-L1-expressing, locally advanced or metastatic non-small-cell lung cancer (KEYNOTE-042): a randomised, open-label, controlled, phase 3 trial. The Lancet. https://doi.org/10.1016/S0140-6736(18)32409-7

3. Gandhi L, Rodríguez-Abreu D, Gadgeel S, Esteban E, Felip E, De Angelis F, Domine M, Clingan P, Hochmair MJ, Powell SF, Cheng SY, Bischoff HG, Peled N, Grossi F, Jennens RR, Reck M, Hui R, Garon EB, Boyer M, Rubio-Viqueira B, Novello S, Kurata T, Gray JE, Vida J, Wei Z, Yang J, Raftopoulos H, Pietanza MC, Garassino MC (2018) Pembrolizumab plus Chemotherapy in Metastatic Non-Small-Cell Lung Cancer. N Engl J Med. https:// doi.org/10.1056/NEJMoa1801005

4. Paz-Ares L, Luft A, Vicente D, Tafreshi A, Gümüş M, Mazières J, Hermes B, Çay Şenler F, Csőszi T, Fülöp A, Rodríguez-Cid J, Wilson J, Sugawara S, Kato T, Lee KH, Cheng Y, Novello S, Halmos B, Li X, Lubiniecki GM, Piperdi B, Kowalski DM (2018) Pembrolizumab plus Chemotherapy for Squamous Non-SmallCell Lung Cancer. N Engl J Med. https://doi.org/10.1056/NEJMo a1810865

5. Gray J, Rodríguez-Abreu D, Powell SF, Hochmair MJ, Gadgeel S, Esteban E, Felip E, Speranza G, De Angelis F, Dómine M, Cheng SY, Bischoff HG, Peled N, Reck M, Hui R, Garon EB, Boyer M, Kurata T, Yang J, Jensen E, Souza F, Garassino MC (2021) FP1.302 Pembrolizumab + Pemetrexed-Platinum vs PemetrexedPlatinum for Metastatic NSCLC: 4-Year Follow-up From KEYNOTE-189. J Thorac Oncol. https://doi.org/10.1016/j.jtho.2021. 01.141

6. Reck M, Rodríguez-Abreu D, Robinson AG, Hui R, Csőszi T, Fülöp A, Gottfried M, Peled N, Tafreshi A, Cuffe S, O'Brien M, Rao S, Hotta K, Leal TA, Riess JW, Jensen E, Zhao B, Pietanza MC, Brahmer JR (2021) Five-Year Outcomes With Pembrolizumab Versus Chemotherapy for Metastatic Non-Small-Cell Lung Cancer With PD-L1 Tumor Proportion Score $\geq 50 \%$. JCO. https://doi.org/10.1200/JCO.21.00174

7. Peters S, Dafni U, Perol M, Felip E, Polito L, Pal N, Ton TGN, Merritt D, Morris S, Stahel RA (2021) VP2-2021: Effectiveness of PD-(L)1 inhibitors alone or in combination with platinumdoublet chemotherapy in first-line (1L) non-squamous non-small cell lung cancer (Nsq-NSCLC) with high PD-L1 expression using real-world data. Ann Oncol. https://doi.org/10.1016/j.annonc. 2021.03.195

8. Dudnik E, Moskovitz M, Rottenberg Y, Lobachov A, Mandelboim R, Shochat T, Urban D, Wollner M, Nechushtan H, Rotem O, Zer A, Daher S, Bar J (2021) Pembrolizumab as a monotherapy or in combination with platinum-based chemotherapy in advanced non-small cell lung cancer with PD-L1 tumor proportion score (TPS) $\geq 50 \%$ : real-world data. OncoImmunol. https://doi.org/10. 1080/2162402X.2020.1865653

9. Eisenhauer EA, Therasse P, Bogaerts J, Schwartz LH, Sargent D, Ford R, Dancey J, Arbuck S, Gwyther S, Mooney M, Rubinstein L, Shankar L, Dodd L, Kaplan R, Lacombe D, Verweij J (2009) New response evaluation criteria in solid tumours: revised 
RECIST guideline (version 1.1). Eur J Cancer. https://doi.org/10. 1016/j.ejca.2008.10.026

10. National Cancer Institute Cancer Therapy Evaluation Program (2017) Common Terminology Criteria for Adverse Events (CTCAE) I Protocol Development I CTEP . In: . https://ctep.cancer.gov/protocolDevelopment/electronic_applications/ctc.htm\# ctc_50. Accessed Apr 11, 2021

11. Kanda Y (2013) Investigation of the freely available easy-to-use software "EZR" for medical statistics. Bone Marrow Transplant. https://doi.org/10.1038/bmt.2012.244

12. Cho BC, Wu Y, Lopes G, Kudaba I, Kowalski DM, Turna HZ, De Castro G, Jr, Caglevic C, Zhang L, Karaszewska B, Laktionov KK, Srimuninnimit V, Bondarenko I, Kubota K, Yin L, Lin J, Souza F, Mok TSK (2021) FP13.04 KEYNOTE-042 3-Year Survival Update: 1L Pembrolizumab vs Platinum-Based Chemotherapy for PD-L1+ Locally Advanced/Metastatic NSCLC. Journal of Thoracic Oncology. doi: https://doi.org/10.1016/j.jtho.2021.01. 143

13. Gadgeel S, Rodríguez-Abreu D, Speranza G, Esteban E, Felip E, Dómine M, Hui R, Hochmair MJ, Clingan P, Powell SF, Cheng SY, Bischoff HG, Peled N, Grossi F, Jennens RR, Reck M, Garon EB, Novello S, Rubio-Viqueira B, Boyer M, Kurata T, Gray JE, Yang J, Bas T, Pietanza MC, Garassino MC (2020) Updated Analysis From KEYNOTE-189: Pembrolizumab or Placebo Plus Pemetrexed and Platinum for Previously Untreated Metastatic Nonsquamous Non-Small-Cell Lung Cancer. JCO. https://doi. org/10.1200/JCO.19.03136

14. Brahmer JR, Rodriguez-Abreu D, Robinson AG, Hui R, Csőszi T, Fülöp A, Gottfried M, Peled N, Tafreshi A, Cuffe S, O'Brien M, Rao S, Hotta K, Leal TA, Riess JW, Jensen E, Zhao B, Pietanza MC, Reck M (2020) LBA51 KEYNOTE-024 5-year OS update: First-line (1L) pembrolizumab (pembro) vs platinum-based chemotherapy (chemo) in patients (pts) with metastatic NSCLC and PD-L1 tumour proportion score (TPS) $\geq 50 \%$. Ann Oncol. https:// doi.org/10.1016/j.annonc.2020.08.2284

15. Paz-Ares L, Vicente D, Tafreshi A, Robinson A, Soto Parra H, Mazières J, Hermes B, Cicin I, Medgyasszay B, Rodríguez-Cid J, Okamoto I, Lee S, Ramlau R, Vladimirov V, Cheng Y, Deng X, Zhang Y, Bas T, Piperdi B, Halmos B (2020) A Randomized,
Placebo-Controlled Trial of Pembrolizumab Plus Chemotherapy in Patients With Metastatic Squamous NSCLC: Protocol-Specified Final Analysis of KEYNOTE-407. J Thorac Oncol. https:// doi.org/10.1016/j.jtho.2020.06.015

16. Allegra C, Blanke C, Buyse M, Goldberg R, Grothey A, Meropol NJ, Saltz L, Venook A, Yothers G, Sargent D (2007) End Points in Advanced Colon Cancer Clinical Trials: A Review and Proposal. JCO. https://doi.org/10.1200/JCO.2007.12.1368

17. Shinno Y, Goto Y, Watanabe S, Sato J, Morita R, Matsumoto Y, Murakami S, Kanda S, Horinouchi H, Fujiwara Y, Yamamoto N, Ohe Y, M.D. (2018) Evaluation of time to failure of strategy as an alternative surrogate endpoint in patients with lung cancer with EGFR mutations. ESMO Open. https://doi.org/10.1136/esmoo pen-2018-000399

18. Huang M, Lou Y, Pellissier J, Burke T, Liu FX, Xu R, Velcheti V (2017) Cost Effectiveness of Pembrolizumab vs. Standard-of-Care Chemotherapy as First-Line Treatment for Metastatic NSCLC that Expresses High Levels of PD-L1 in the United States. Pharmacoecon. https://doi.org/10.1007/s40273-017-0527-z

19. Insinga RP, Vanness DJ, Feliciano JL, Vandormael K, Traore S, Ejzykowicz F, Burke T (2019) Cost-effectiveness of pembrolizumab in combination with chemotherapy versus chemotherapy and pembrolizumab monotherapy in the first-line treatment of squamous non-small-cell lung cancer in the US. Curr Med Res Opin. https://doi.org/10.1080/03007995.2019.1571297

20. Barbier MC, Pardo E, Panje CM, Gautschi O, Lupatsch JE, for the Swiss Group for Clinical Cancer Research, (SAKK) (2021) A cost-effectiveness analysis of pembrolizumab with or without chemotherapy for the treatment of patients with metastatic, nonsquamous non-small cell lung cancer and high PD-L1 expression in Switzerland. Eur J Health Econ. https://doi.org/10.1007/ s10198-021-01282-4

Publisher's Note Springer Nature remains neutral with regard to jurisdictional claims in published maps and institutional affiliations. 